appropriate elimination diets introduced early. These measures promote optimal nutrition and growth (2) and may also serve as secondary prevention of atopy.

Acknowledgements.-This study was supported by the Medical Research fund of Tampere University Hospital (TA) and the Academy of Finland (EI).

\section{References}

1. Hanifin JM. Epidemiology of atopic dermatitis. Monogr Allergy 1987; 21: 116-31

2. Isolauri E, Tahvanainen A, Peltola T, Arvola T. Breast-feeding of allergic infants. J Pediatr 1999; 134: 27-32
3. Bergman RL, Edenharter G, Bergman KE, Forster J, Bauer CP, Wahn V, et al. Atopic dermatitis in early infancy predicts allergic airway disease at 5 years. Clin Exp Allergy 1998; 28: 965-70

4. David TJ. Infant feeding causes all cases of asthma, eczema, and hay fever. Or does it? Arch Dis Child 1998; 73: 97-8

T Arvola, J Hvitfelt-Koskelainen ${ }^{1}$, U-M Eriksson ${ }^{1}$, A Tahvanainen and E Isolauri, Medical School, University of Tampere and Department of Paediatrics, Tampere University Hospital, Tampere, Finland; Department of Paediatrics ${ }^{1}$, University of Turku, Turku, Finland. Correspondence to: T Arvola, Medical School, University of Tampere, PO Box 607, 33101 Tampere, Finland (Tel. +358 3215 6059, fax. +35832156164, e-mail.kltaar@uta.fi)

Received Oct. 1, 1999. Accepted in revised form Oct. 26, 1999

\title{
Breastfeeding rates among hyperphenylalaninemic infants
}

Sir,

Recent emphasis has been placed on the notion that all infants might be breastfed as long as possible, that is, for $12 \mathrm{mo}$ at least and even longer, possibly up to $2 \mathrm{y}$ of age. The advantages deriving from breastfeeding are now widely recognized (1) and even in the case of infants of HIV mothers might be beneficial (2).

There is a group of disorders in which breastfeeding may often be limited or suppressed for reasons other than the simple desire of the mother to formula-feed or the medical advice not to breastfeed. These are the inborn errors of metabolism at early clinical expression or identified through the screening of the newborn. The latter includes hyperphenylalaninemic syndromes. Hyperphenylalaninemias (HPA: deficiency of the phenylalanine, Phe, hydroxylase enzyme) are recognized early and are the most common errors of amino acid metabolism. In countries where newborn screening is mandatory, HPA babies are usually identified and put on dietary treatment (i.e. a low-Phe diet) within 1 mo of life. Breastfeeding in HPA infants has beneficial longterm effects on developmental performance (3). This is technically feasible since human milk is relatively low in Phe and may be continued under medical supervision (4). Mothers could theoretically keep on breastfeeding their babies provided that they follow a close assessment of the blood Phe levels through the Guthrie test in order to modify, if required, the dietary schedules. Unfortunately, after diagnosis, mothers may develop a form of anxiety towards every type of food being "natural", containing Phe compared to Phe-free "adhoc" synthetic products.

We checked the breastfeeding rates in a group of 33
HPA subjects born in the 1994-98 period, and consecutively admitted to our department for confirmation of the diagnosis of HPA, and compared these with the breastfeeding rates in Italy (3). The median age at admission was $18 \mathrm{~d}$ (range 14-22). After diagnosis, mothers had been encouraged to maintain breastfeeding for most meals and to supplement with Phe-free formulas to reach the daily caloric and amino acid needs. The meals at the breast were allowed based on the average calculated Phe intake and the individual tolerance, assessed through bi-weekly Guthrie cards in the first $3 \mathrm{mo}$ and then once per week. In the case of lack of human milk, a standard infant formula with a low protein content $(1.4 \mathrm{mg} / \mathrm{dL})$ was introduced to supply the Phe quota necessary for growth. Clinical assessments for the evaluation of growth and feeding problems were carried out monthly. Based on the

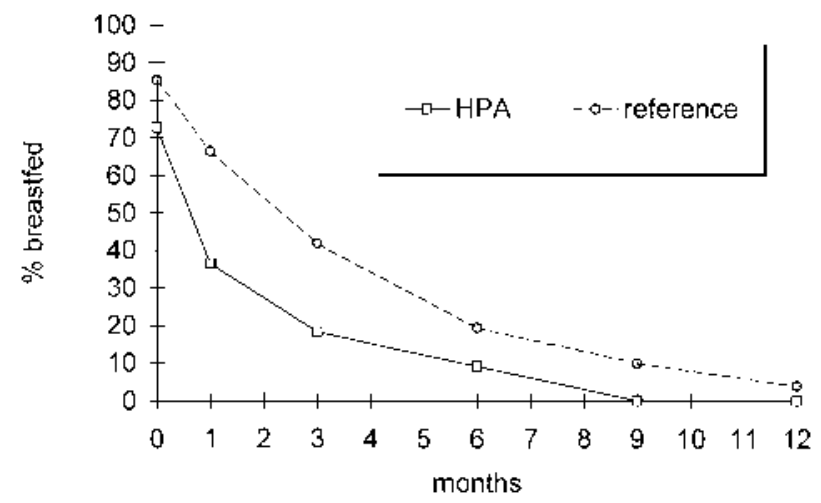

Fig. 1. Rates of any type of breastfeeding. 
WHO definitions of breastfeeding (Nutrition Unit, WHO, Geneva, 1996), we collected information on all types of breastfeeding (exclusive + Phe-free formula, predominant + Phe-free formula, breastfeeding + minimal amounts of adapted formula + Phe-free formula). The curves of the 1-y breastfeeding duration were calculated in accordance with the Kaplan-Meier method and compared using the log-rank test. The rates (\%) of breastfeeding during the first year of life in HPA infants compared with the general population are reported in the Figure. The rates of $1-y$ duration are lower in the HPA group ( $p<0.001, \log$-rank test). In our sample, also initiation rates are lower in the study population. So, we may conclude that breastfeeding duration rates in HPA infants are notably lower than in the general population for any type of breastfeeding. We speculate that the diagnosis of a chronic disorder requiring a strict clinical and dietary control may negatively affect the maternal attitude towards breastfeeding. After diagnosis of HPA, mothers need psychological and technical support to maintain breastfeeding in order to gain the expected advantages on infant outcome and the mother-infant relationship.

\section{References}

1. Editorial. A warm chain for breastfeeding. Lancet 1995; 344: $1239-41$

2. Coutsoudis A, Pillay K, Spooner E, Kuhn L, Coovadia HM. Influence of infant-feeding patterns on early mother-to-child transmission of HIV-1 in Durban, South Africa: a prospective cohort study. Lancet 1999; 354: 471-6

3. Riva E, Agostoni C, Biasucci G, Trojan S, Luotti D, Fiori L, Giovannini M. Early breastfeeding is linked to higher intelligence quotient scores in dietary treated phenylketonuric children. Acta Paediatr 1996; 85: 56-8

4. Berry HK. Special and therapeutic formulas for inborn errors of metabolism. In: Tsang RC, Nichols BL, editors. Nutrition during infancy. Hanley \& Belfus, Inc., 1988; 340-59

5. Riva E, Banderali G, Agostoni C, Silano M, Radaelli G, Giovannini M. Factors associated with initiation and duration of breastfeeding in Italy. Acta Paediatr 1999; 88: 411-5

C Agostoni, E Verduci, L Fiori, E Riva and M Giovannini, Department of Paediatrics, San Paolo Hospital, 8 Via A, di Rudini, 20142 Milan, Italy (Tel. +3902 89158665, fax. +3902 89126846, e-mail.agostoc@tin.it)

\section{Influence of fever on total cholesterol and triglyceride levels in childhood}

Sir,

Dyslipidaemia is one of the major risk factors for ischaemic heart disease, being related to the beginning and spread of fatty deposits on the arterial walls from as early as childhood. Since it is usually asymptomatic at this age, screening, diagnosis and evaluation studies are based on the determination of the serum lipid levels (1$3)$.

Previous studies have pointed out that fever by itself can alter the lipid profile and that this fact should be taken into account when determinations are carried out (4). We would like to present some new data supporting this affirmation.

A retrospective analysis was conducted on the total cholesterol (TC) and triglyceride (TG) levels of 466 children (284 males and 182 females) aged 2-8y (average $4.42 \pm 1.5$ ) admitted to the Hospital Niño Jesús in Madrid with different febrile diseases.

They were divided into several groups: those with fever at the moment when the sample was taken $(n=$ $306)$ were classified into: $<2 \mathrm{~d}$ with fever $(n=88), 3-$ $4 \mathrm{~d}$ with fever $(n=116)$ and $\geq 5 \mathrm{~d}$ with fever $(n=102)$. Those who were afebrile at the moment of the test $(n=$
160) were divided into 2 groups: $<2 \mathrm{~d}$ without fever $(n=98)$ and $\geq 3 \mathrm{~d}$ without fever $(n=62)$.

Eighty-four of the children admitted had a second analysis taken 2 wk after the fever had disappeared. This second sample was not taken because of this study.

None of the children had a past medical history of diabetes, nephrosis, thyroid or liver disease. None had been admitted to the intensive care unit or had received parenteral feeding. Therapy included antibiotics and antipyretic drugs; no glucocorticoids were used in any case.

The average total cholesterol level was significantly lower $\left(3.77 \pm 0.82 \mathrm{mmol} \mathrm{l}^{-1}\right)$ and the average triglyceride level significantly higher $\left(1.15 \pm 0.53 \mathrm{mmol}^{-1}\right)$ than those obtained in 544 healthy children in previous studies conducted by our work group (TC: $4.39 \pm$ $0.73 \mathrm{mmol} \mathrm{l}^{-1}, p<0.001$; TG: $0.68 \pm 0.25 \mathrm{mmol} \mathrm{l}^{-1}$, $p<0.001)(5,6)$.

No statistical differences were found in the values of the total cholesterol or of triglycerides regarding the gender or the age of the children.

The 306 children who had a fever when the sample was collected showed lower cholesterol (3.67 \pm 